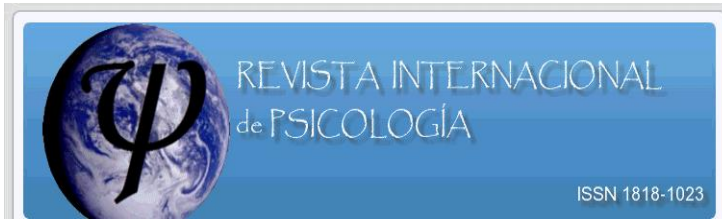

\title{
EL "BURN OUT": EL SÍNDROME DE ESTAR QUEMADO EN EL TRABAJO
}

\author{
Lic Sonia Cesio ${ }^{\mathrm{a}}$
}

Estamos atravesando un momento histórico y socio económico que plantea profundos cambios asociados a la disminución de las posibilidades laborales, y a la desprotección del estado, lo que produce desamparo y vulnerabilidad social y personal.

Esta circunstancia plantea a cada individuo la modificación de sus hábitos, y con ello el diseño permanente de estrategias para competir con la 'economia de mercado' donde los servicios profesionales se legitiman como 'mercancía', ya que circula la premisa de 'libre elección', pero de acuerdo al nivel adquisitivo de los consumidores privados.

Cuando irrumpe la realidad externa con una cualidad traumática se produce un trastocamiento entre la realidad interna y la externa, impactando a los sujetos en forma variada. Es una violencia ajena al sujeto, que se ubica en la realidad externa, pero resuena en su interioridad y produce inquietud, perplejidad, tendencia al aislamiento y exclusión. Es una destitución que opera en la condición subjetiva y esta al servicio de la producción de "desexistentes...término empleado para designar...a las personas que de un momento a otro quedan destituidas de su lugar en el sistema laboral" (1)

En la actualidad se han destruido los referentes sociales tradicionales, aquellos que nos daban las certidumbres por las cuales se armaba un proyecto de vida, se elegía un trabajo que se mantenía, y un cierto modo de vivir. Esta circunstancia nos genera inestabilidad permanente, tanto en el ámbito individual, social e institucional.

Las crisis de esta naturaleza, con la destrucción del orden establecido previamente instalan el estado de necesidad, hay coerción anímica y predomina la resolución de los apremios instintivos, desjerarquizando la función del pensamiento y la posibilidad de espera. Es un ataque a la autoestima, disminuyendo la posibilidad de pensar estrategias útiles frente a un futuro sombrío.

El reconocimiento de la realidad externa se relaciona directamente con la interacción que se lleva a cabo con ella; con el lenguaje común, y con mayor acceso a lo simbólico.

Cada sujeto vive e investiga los sucesos de la vida cotidiana. Cuando los mensajes provenientes de ella son confusos, se producen alteraciones de diferente orden.

\footnotetext{
${ }^{a}$ Coordinadora, redactora de contenidos y webmaster de www.enigmapsi.com.ar Correo electrónico: info@enigmapsi.com.ar scesio@2vias.com.ar
} 
El aspecto social de cada individuo lo incluye en una historia vivida y otra por vivir; se transforma en el emisor de una organización social; tiene un sentido de pertenencia con el entorno y se organiza en función de reglas y leyes. Cuando existe violencia social de esta naturaleza, hay una transgresión de la ley y ello reduce la vida vincular, la socialización $\underline{(2)}$

Las consecuencias en la vida subjetiva son:

1. Los efectos de lo impensable y

2. El estrés laboral y sus consecuencias.

El fenómeno de lo impensable se refiere a ciertas percepciones que despiertan emociones intolerables, despertado por la sensación de inutilidad por la edad ( entre las personas mayores de 40 años) y la posibilidad de ser un elemento superfluo en una sociedad empobrecida. Son emociones muy difíciles de poner en palabras ya que producen parálisis del pensamiento. "La catástrofe no es lo que ocurre ahí afuera, sino lo que nos ocurre: el riesgo de devenir superfluos es una condición del

pensamiento...estamos transitando una circunstancia en que se agota una realidad de la que formaba parte un modo de pensar" (3)

La reorganización depende de: enfrentar el miedo y pensar en él; de hacer un revelamiento de la situación externa; un nuevo reconocimiento de capacidades propias en cuanto a habilidades y funciones mentales) y establecer nuevos vínculos, creando otras interacciones para salir del aislamiento. "Cuando sobreviene...un corte en la regularidad de la vida...lo que se haga de ahí en mas adquiere otro sentido...se establece como diferente de la vida previa...genera otra vida, otra subjetividad" (4)

El Síndrome de Burnout o Estrés Laboral esta calificado por la Organización Mundial de la Salud como epidemia mundial y se lo considera como un trastorno adaptativo crónico. Describe su producción en entornos laborales exentos de la satisfacción intrínseca a la realización de la tarea y surge cuando el profesional ve frustradas sus expectativas de modificación de la misma: es un síndrome y por lo tanto, tiene consecuencias.

Comienza con aparición de angustia y sentimientos de frustración (que se traduce como agotamiento emocional), trastornos en los ritmos de alimentación, de la actividad física, aparecen dolencias físicas y psíquicas, y un sentimiento de inadecuación a las tareas. 
En el comportamiento laboral se observan dos situaciones polares (opuestas) en cuanto a la respuesta:

1. Un desapego notorio, como si no se tuviera en cuenta la aparición de la situación de emergencia;

2. Un exceso de compromiso, que se observa en aquella persona que no descansa lo suficiente, trabaja en el tiempo libre, etc.

Íntimamente hay un profundo cambio en la manera de sentir, de actuar en relación a como se lo había hecho previamente, y denota una perdida de la motivación para involucrarse nuevamente.

Son mas proclives a sufrir este síndrome aquellos profesionales cuyo actividad se desarrolla en contacto con personas, como el personal sanitario, de la enseñanza, asistentes sociales, los letrados que litigan, etc.

Hay que incluir el rol de las instituciones, las que habitualmente nos proporcionan ideas comunes y lugares de pertenencia, un grupo con quien interaccionar, la posibilidad de generar pensamientos sobre el presente y el provenir; los limites, la identidad profesional.

En el atravesamiento de estas crisis, los valores que constituyen a las instituciones entran en contradicción, dejan de aportar la función de sostén y nos sentimos abandonadas por ellas, vivenciándose abandono y desamparo por efecto de la violencia que circula. Allí sobrevienen alteraciones. Estos enormes esfuerzos de adaptación empobrecen el pensamiento, dañan la subjetividad y tambalea la identidad. "El apartamento entre la cultura de la institución y el funcionamiento psíquico inducido por la tarea, esta en la base de la dificultad para instaurar o mantener un espacio de contención, de conexión y transformación...Importa dejar hablar y escuchar al sufrimiento...venga de donde viniere y apunte a donde apuntare: la condición primordial

Es dejar que advenga su representación, mediante la palabra y mediante el juego" (5)

Cuando la situación laboral es tan conflictiva se siente como si no quedara espacio para la persona individual, como si la vida personal se confundiera con la vida laboral y se correlaciona con un estado mental de desarticulación, se alteran paulatinamente las reglas que rigen la interacción y el contexto social se vuelve incomprensible, inasible. Consecuentemente los grupos de pertenencia se desorganizan y los de referencia se pierden (7) 


\section{Estrategias para afrontar esta problemática}

Hay factores para tener en cuenta respecto de este síndrome y la repercusión sobre la calidad de vida. Ellos son: la vulnerabilidad, la resiliencia y los sistemas de apoyo.

Vulnerabilidad: abarca a los recursos psíquicos y sociales del sujeto en cuestión, pero se relaciona directamente con la problemática padecida y el contexto en el que ocurre, en tanto productores de vulnerabilidad. Hay que sumarle la identificación profesional especifica (no es lo mismo hacer docencia en vez de asistencia que manejar un taxi).

Resiliencia: es lo opuesto a vulnerabilidad. Abarca lo que "es elástico, aquello que se puede recuperar de la vida primitiva...para buscar otras salidas y favorecer procesos integradores" (6). Se destaca la resistencia individual frente a factores dañinos, y la capacidad para mantener la integridad frente a circunstancias difíciles y tolerancia a los cambios que afectan la cotidianeidad. Las herramientas psíquicas a las que hay que recurrir son: revalorar la capacidad de pensar, darle otro valor a la vida que se corresponda con la vida actual, revisar la autoestima y resignificar la angustia como señal de alarma, en pos de reencontrar el equilibrio perdido.

Sistemas de apoyo: son aquellos que refuerzan los sistemas de competencia y le permiten a un sujeto afrontar situaciones de riesgo. Ellos son la familia, los amigos, las organizaciones de ayuda que actúen en forma espontánea y que proporcionen confianza y sostén. También cuentan los recursos materiales y económicos con los que se puede contar.

Las sugerencias son: instituir una nueva rutina, intercambiar con profesionales de la misma especialidad, reorganizar el ambiente laboral y si no se producen las modificaciones esperadas, solicitar apoyo psicológico. 


\section{BIBLIOGRAFÍA}

(1) “La crueldad: una práctica deshumanizante" por Puget, Janine -en Clinica Psicoanalitica ante las Catastrofes Sociales. La experiencia argentina" - Pg 162 - Ed Paidos - 2003 -

(2) "Violencia social transgresora" Puget, J; Bianchedi, E T de; y otros - Gaceta Psicológica N 94 - Asociacion de Psicologos de Bs As - 1993 -

(3) "Conceptualización de catastrofe social. Límites y encrucijadas" por Lewkowicz, Ignacio - Idem - Pg 63/64 -

(4) “Los "haceres” y los espacios psíquicos” por Berentein, I - Edem - Pg 87 -

(5) "Realidad psíquica y sufrimiento en las instituciones " en La institución y las instituciones" Estudios psicoanalíticos. Kaes, René y otros (1989). Bs. As. Argentina. - Editorial Paidos

(6) "El estrés y sus destinos. Que importa este concepto para la psicologia de hoy" Frenguelli, Roberto C - en Cuadernos del estudiante - Año1 - N 2 - 2005 - ADEIP - Rosario

(7) "Estado de amenaza" por Janine Puget en Violencia de Estado y Psicoanalisis - Puget. J; Käes, R; Pelento, M L y otros - Bibliotecas Universitarias - Centro Editor de America Latina - APDH - 1991

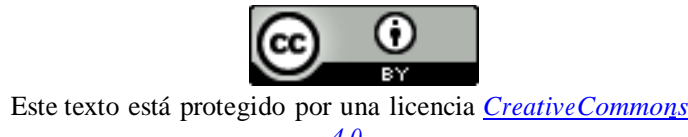

4.0.

Usted es libre para Compartir — copiar y redistribuir el material en cualquier medio o formato - y Adaptar el documen- to - remezclar, transformar y crear a partir del material- para cualquier propósito, incluso comercialmente, siempre que cumpla la condición de:

Atribución: Usted debe reconocer el crédito de una obra de manera adecuada, proporcionar un enlace a la licencia, e in- dicar si se han realizado cambios. Puede hacerlo en cualquier forma razonable, pero no de forma tal que sugiera que tie- ne el apoyo del licenciante o lo recibe por el uso que hace. 